\title{
Beacon Nucleic Acid Ligands of Agar Magnetic Beads Mediated Immune PCR Detection of Hbsag
}

\author{
Li Dongdong ${ }^{1}$, Liao Shiqi ${ }^{2,}$ ", Yuan Hongxia ${ }^{2}$, Zhao Yunwang ${ }^{3}$, Li Xing ${ }^{3}$, Wang Jing ${ }^{3}$, Wang Jin ${ }^{3}$, \\ Tian Caiping ${ }^{2}$, Wei Zhengli ${ }^{2}$ \\ ${ }^{1}$ Gansu Province Medical Science Research Institute and College of Life Science of Cell Biology, Lanzhou University, Lanzhou, China \\ ${ }^{2}$ Gansu Province Medical Science Research Institute, Lanzhou, China \\ ${ }^{3}$ Department of Biochemistry and Molecular Biology, Northwest Normal University, Lanzhou, China
}

\section{Email address:}

ddli14@1zu.edu.com (Li Dongdong), 1shiqi@126.com (Liao Shiqi)

${ }^{*}$ Corresponding author

\section{To cite this article:}

Li Dongdong, Liao Shiqi, Yuan Hongxia, Zhao Yunwang, Li Xing, Wang Jing, Wang Jin, Tian Caiping, Wei Zhengli. Beacon Nucleic Acid Ligands of Agar Magnetic Beads Mediated Immune PCR Detection of Hbsag. Science Discovery. Vol. 4, No. 5, 2016 , pp. $285-291$. doi: $10.11648 /$ j.sd.20160405.14

Received: August 1, 2016; Accepted: August 29, 2016; Published: October 13, 2016

\begin{abstract}
Severe hepatitis disease risk, mortality is high in the diagnosis of phenotypic showed the most late for hepatitis, diagnosis and treatment has been late right now, therefore, can find a effective, sensitive, rapidly and accurately identify antigen of second liver surface, the method of early diagnosis and treatment of hepatitis b virus infection has very important significance. In this article, we use mouse IgG Fc fragment nucleic acid beacon as the detection molecules to detecte HBsAg, The 5 'end of the ligand binds a double-stranded beacon sequence as detection molecules, which has specific binding capacity for mouse IgG Fc fragment. A carboxyl group of agarose beads was used as a carrier of combining with hepatitis B goat anti-human polyclonal antibody as a capture molecule to catch hepatitis B virus surface antigen in the liquid to be detected, then combining with mouse anti-human IgG immunoglobulin for HBsAg and nucleic acid beacon to form beads-Polyclonal Antibody-antigen-monoclonal antibody-beacon complexes. Hepatitis B surface antigen quantitative detection technology was achieved by using Real Time-PCR to detect nucleic acid beacon. We termed the detection technology as Immune-PCR detection technology, which is a fast, stable, accurate and sensitive technology for hepatitis B surface antigen detection, In clinic for the early diagnosis and treatment of hepatitis b virus (HBV) infection has very important significance.
\end{abstract}

Keywords: Carboxyl Agarose Beads, Nucleic Acid Beacon, HBsAg, Hepatitis B Mouse Anti-human IgG, Immune-PCR

\section{琼脂磁珠介导的核酸信标配基免疫PCR检测 HBsAg}

\author{
李东东 ${ }^{1}$, 廖世奇 ${ }^{2 *}$, 袁红霞 ${ }^{2}$, 赵运旺 ${ }^{3}$, 李星 ${ }^{3}$, 王靖 ${ }^{3}$, 王进 $^{3}$, 田彩平 ${ }^{2}$, 魏政丽 ${ }^{2}$ \\ ${ }^{1}$ 甘肃省医学科学研究院和生命科学学院细胞生物学, 兰州大学, 兰州, 中国 \\ ${ }^{2}$ 甘肃省医学科学研究院, 兰州, 中国 \\ ${ }^{3}$ 生化与分子生物学, 西北师范大学, 兰州, 中国
}

邮箱

ddli14@1zu. edu. com（李东东）, 1shiqi@126.com（廖世奇）

摘要: 重症肝炎病情危险, 死亡率高诊断表型表现出时大都为肝炎晚期, 此时诊断治疗已晚, 因此, 找到一种能高效、 灵敏、快速准确地识别乙肝表面抗原的方法, 对乙肝病毒感染的早期诊断和治疗具有非常重要的意义。本文采用小鼠 IgG 的 Fc核酸信标配基为检测分子，该分子的配基是对小鼠 $\operatorname{lgG}$ 的 Fc 具有特异性结合能力，配基的 5' 端上连接一个双链的 
信标序列组成的检测分子。本实验以羧基琼脂糖磁珠为载体, 结合乙肝山羊抗人多克隆抗体为捕捉分子, 捕捉检测液 中的乙肝病毒表面抗原, 再结合乙肝小鼠抗人HBsAg的IgG免疫球蛋白和核酸信标配基, 形成磁珠-多抗-抗原-单抗一配 基信标复合物, 利用Real Time-PCR对信标配基检测，间接完成对HBsAg定量的检测技术。该技术是快速、稳定、准确、 灵敏地检测微量乙肝表面抗原的免疫-PCR检测技术, 在临床上对乙肝病毒感染的早期诊断和治疗具有非常重要的意义。

关键词：羧基琼脂糖磁珠，核酸信标配基，HBsAg，乙肝小鼠抗人的 IgG，免疫-PCR

\section{1. 引言}

乙型肝炎病毒表面抗原 $(H B s A g)$ 是HBV 感染的主要标 志, 是决定病毒吸附感染细胞受体的成分, 也是HBV感染者 最早出现的血清学指标, 是乙肝早期诊断的重要指标 $[1,2]$ 。重症肝炎病情危险, 死亡率高现有的诊断标准如: 重度乏力, 胆红素升高, 腹水, 肝性脑病等表型大都为肝 炎晚期症状，此时诊断治疗已晚，[3]因此, 找到一种能高 效、灵敏、快速准确地识别乙肝表面抗原的方法, 对乙肝 病毒感染的早期诊断和治疗具有非常重要的意义。

酶联免疫（ELISA）双抗体夹心法是检测抗原最常用 的方法, Ocama P等 $[4]$, 张涵等 [5], 欧阳颖等 $[6]$ 利用此 方法检测HBV微量蛋白的浓度, 但测定结果不理想, 因此 我们引进核酸信标配基免疫PCR来检测HBsAg。

核酸信标配基是在配基的 5 ’ 端连接一段带有苂光标 记探针的双链核苷酸序列与一个已知特异性靶分子的核 酸适配体制备而成的, 是在核酸适配体的基础上衍生出的 一种新的检测分子, 其既具有核酸适配体的识别能力又具 有信号储存、传递、放大功能，是一种易于构建、制备、 靶向性强、灵敏度高的检测分子。 $[7,8]$ 本文采用的核酸 信标配基分子能特异性地识别小鼠 IgG免疫球蛋白的Fc片 段, 由于核酸信标是双链, 不影响配基和靶分子(Fc片段) 的结合，因此通过核酸信标结合实时定量PCR检测技术来 完成信息传递和信号放大，间接的定量检测靶分子。

本实验与酶联免疫法相似, 但不同点在于检测抗原的 不是与一抗对应的酶标二抗，而是对一抗有特异性的核酸 信标配基与一抗形成的复合物, 通过实时定量PCR检测来 完成。

\section{2. 材料、方法}

\section{1. 仪器、试剂}

Rotoe-Gene3000 实时苂光定量 PCR 仪: 美国 Rotor-Gene公司BI0-RAD全自动酶标仪; DYY-12型电泳仪; 超净工作台中国苏州净化设备有限公司; B2生物安全柜: 中国上海瑞仰净化设备有限公司; 16 型低温离心机: 中国 长沙平凡仪器仪表有限公司; 戊二醛: 上海生物工程有 限公司; 环氧氯丙烷：上海生物工程有限公司; 乙肝山羊 抗人多克隆抗体 $2 \mathrm{mg} / \mathrm{ml}$; 乙肝表面抗原 $5 \mathrm{mg} / \mathrm{ml}$; 乙肝小 鼠抗人-IgG $2 \mathrm{mg} / \mathrm{ml}$; 乙肝羊抗鼠二抗 $0.2 \mathrm{mg} / \mathrm{ml}$; 乙型肝 炎表面抗原ELISA检测试剂盒: 近岸蛋白质科技有限公司; 底物 $A 、 B$ 终止液; 牛血清白蛋白 (BSA) : 上海生物工程有 限公司; 核酸信标配基库 (由Fc片段核酸配基和核酸信标
组成) 和羧基琼脂糖磁珠 (由中国甘肃省医学科学研究院 生物医学分子中心提供)。

\section{2. 实验方法}

\subsection{1. 捕捉载体的制备}

（1）羧基琼脂糖磁珠的制备

利用包埋法, 以戍二醛作为分散剂将磁性微球分散在 琼脂糖高分子的溶液中，通过絮凝、沉积、蒸发等过程使 得琼脂糖包裹在磁性微粒周围形成形成琼脂糖磁珠。[9] 利用表面化学包覆改性法, 以环氧氯丙烷为偶联剂, 使琼 脂糖磁珠表面带有羧基官能团。[10]

（2）捕捉载体的制备

羧基琼脂糖磁珠作为载体, 包被稀释 100 倍浓度为 $0.02 \mathrm{mg} / \mathrm{ml}$ 的乙肝山羊抗人多克隆抗体, $37^{\circ} \mathrm{C}$ 孵育 $1 \mathrm{~h}$, 制成 羧基琼脂糖的捕捉载体。利用抗原抗体的特异性结合, 捕 捉被检测分子; 结合核酸信标配基作为检测分子。

\section{2. 2. 羧基琼脂磁珠核酸信标配基免疫-PCR对HBsAg的 检测}

(1) 制作标准曲线

取上述捕捉羧基琼脂糖磁珠 4 份, $200 \mathrm{ul} /$ 份于 $1.5 \mathrm{ml}$ 离 心管中, 用强力吸铁石吸住磁珠, 弃去上清; 加入 $1000 \mathrm{ul}$ 1xPBS (PH 7.4) 洗涤磁珠, 每次 3min, 洗涤3次, 第三次把磁珠转移到另一个干净的 $1.5 \mathrm{~m} 1$ 离心管中, 弃去上 清; 加入 4 个依次 10 倍梯度稀释的 $10^{5} \sim 10^{8}$ 乙肝表面抗原标 准品 $20 \mathrm{ul}$ 浓度分别为 $1000 \mathrm{pg}, 100 \mathrm{pg}, 10 \mathrm{pg}, 1 \mathrm{pg}, 37^{\circ} \mathrm{C}$ 恒温振 荡反应 $1 \mathrm{~h}$; 弃去上清, 加入 $1000 \mathrm{ul} 1 \mathrm{XPBS}$ (PH 7.4) 洗涤磁珠, 每次 $3 \mathrm{~min}$, 洗涤3次, 第三次把磁珠转移到另一个干净的 $1.5 \mathrm{ml}$ 离心管中, 弃去上清; 加入稀释 1000 倍浓度为 $1 \mathrm{mg} / \mathrm{ml}$ 的乙肝小鼠抗人的 $\operatorname{IgG}$ 单克隆抗体 $50 \mathrm{u} 1,37^{\circ} \mathrm{C}$ 恒温振荡反应 1h; 弃去上清, 加入 $1000 \mathrm{u} 1$ 1xPBS (PH 7.4) 洗涤磁珠, 每 次 $3 \mathrm{~min}$, 洗涤3次, 第三次把磁珠转移到另一个干净的 $1.5 \mathrm{ml}$ 离心管中, 弃去上清; 加入稀释 1000 倍的小鼠抗人IgG单克 隆抗体的核酸信标配基 $100 \mathrm{u} 1,37^{\circ} \mathrm{C}$ 恒温振荡反应 $1 \mathrm{~h}$; 弃去 上清，用 $1000 \mathrm{u} 11.5 \%$ 的 tween每次 $3 \mathrm{~min}$, 洗涤 5 次, 用 1000u1 1xPBS洗涤一次换管, 再用1000u1DEPC纯水洗涤1次; 加入 $100 \mathrm{u} 1 \mathrm{DEPC}$ 纯水 $95^{\circ} \mathrm{C}$ 加热 $5 \mathrm{~min}, 12000 \mathrm{prm}$ 离心 $5 \mathrm{~min}$, 收 集上清, Real Time-PCR检测。

（2）核酸信标配基免疫-PCR对HBsAg的重复检测

取15管羧基琼脂糖磁珠, 每管 $200 \mathrm{u} 1$, 在5管里加入乙 肝表面抗原标准品, 5管加入待检测的乙肝表面抗原, 5 管加入水作为阴性对照, 其它步骤与制作标准曲线步骤相 同。 


\section{2. 3. ELISA方法对HBsAg的检测}

采用双抗体夹心酶联免疫吸附试验 (ELISA) 作为对照 组。在预包被抗人乙型肝炎病毒表面抗原 (HBsAg) 抗体 (固 相抗体）的微孔酶标板中，加入人乙型肝炎病毒表面抗原 ( HBsAg) 校准品 $5 \mathrm{mg} / \mathrm{ml}$ 和待测样本 $100 \mathrm{ul}$, 再加入另一株 HRP标记的抗鼠乙型肝炎病毒表面抗原 (HBsAg) 抗体（酶 标抗体) $100 \mathrm{ul}$ ，经过 $37^{\circ} \mathrm{C}$ 温育 $1 \mathrm{~h}$, 用 $1 x P B S$ 充分洗涤，去除 未结合的组分，在微孔板固相表面形成固相抗体-抗原-酶 标抗体的夹心复合物。加底物 $\mathrm{A}$ 和B，底物在HRP催化下，产 生蓝色产物, 加入50u1终止液（2M硫酸），在终止液作用 下, 最终转化为黄色, 在酶标仪上 $490 \mathrm{~nm}$ 处测定吸光度 (OD 值），吸光度（OD值）与待测样品中乙型肝炎病毒表面抗 原 (HBsAg) 的浓度正相关。拟合校准品曲线, 可以计算出 样本中乙型肝炎病毒表面抗原（HBsAg）的浓度。

\section{3. 结果}

\section{1. 羧基琼脂磁珠核酸信标配基免疫-PCR对HBsAg的检测}

以羧基琼脂糖磁珠为载体, 包被 100 倍稀释浓度为 $0.02 \mathrm{mg} / \mathrm{ml}$ 的乙肝山羊抗人多克隆抗, 检测 4 个 $10^{5}-10^{8}$ 倍梯 度稀释浓度为 $1000 \mathrm{pg}, 100 \mathrm{pg}, 10 \mathrm{pg}, 1 \mathrm{pg}$ 的乙肝表面抗原, 1 个阴性对照和 1 个体系空白, 用小鼠 $\operatorname{IgG}$ 的Fc核酸信标配基 进行检测, 每管加入模板6u1。如图1、如图2可以看到在 $10^{5}-10^{8}$ 的定量域内 HBsAg 具有线性关系, 可以检测出待测 蛋白量。

以羧基琼脂糖磁珠为载体, 包被 100 倍稀释浓度为 $0.02 \mathrm{mg} / \mathrm{ml}$ 的乙肝山羊抗人多克隆抗体, 包被乙肝表面抗 原的待检测液, 以小鼠 $\mathrm{IgG}$ 的 $\mathrm{Fc}$ 核酸信标配基为DNA模板, 在同样的反应条件下设置 16 孔重复检测 $10^{7}$ 倍稀释的 $\mathrm{HBsAg}$ 样品 $5 \mathrm{mg} / \mathrm{ml}$ 和乙肝表面抗原的待检液, 再加入 1000 稀释得小鼠抗人 $\mathrm{IgG}$ 单克隆抗体和以小鼠 $\mathrm{IgG}$ 的 $\mathrm{Fc}$ 核酸信 标配基, 实时定量-PCR检测, 已验证样品检测的稳定性。 如图3可以看到HBsAg检测结果具有重复性。统计结果表明, 16 个检测值待检液Ct值SD值不足 0.05 , 优势显著。

表1 不同浓度HBsAg 对应的CT值。

\begin{tabular}{llllll}
\hline HBsAg浓度 & $1 \mathrm{pg}$ & $10 \mathrm{pg}$ & $100 \mathrm{pg}$ & $1000 \mathrm{pg}$ & water \\
\hline $\mathrm{CT}$ 值 & 27.78 & 21.26 & 17.78 & 12.80 & 36.27 \\
\hline
\end{tabular}

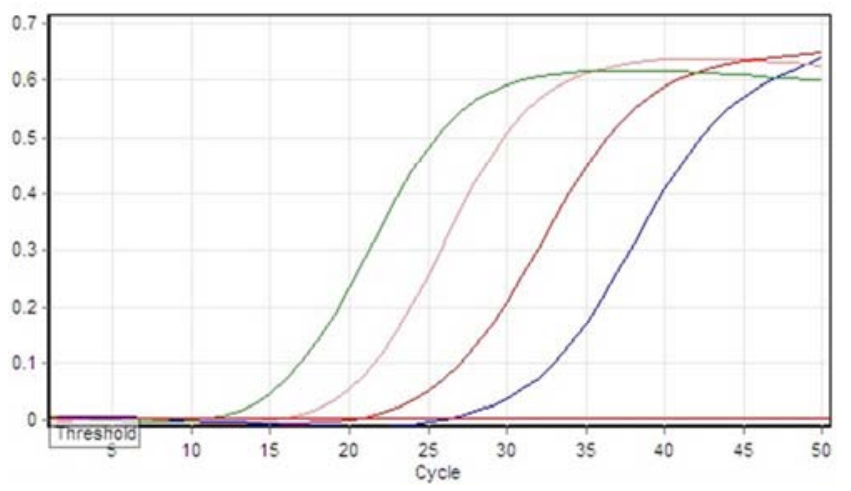

图1 HBsAg检测的定量曲线。
图 1 免疫 PCR 检测 HBsAg 的定量曲线: 抗原浓度分别为 (a) : 1000pg (b) :100pg (c) :10pg (d) :1pg结果显示: 实时定量-PCR检测的 $\mathrm{Ct}$ 值随着抗原浓度的降低而增加。

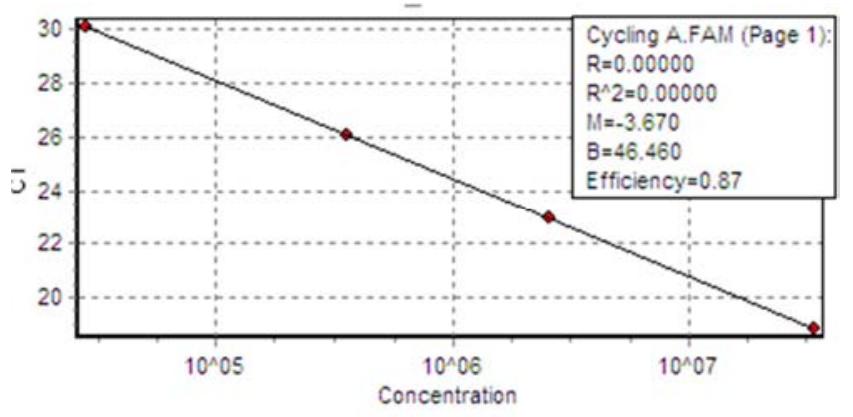

图2 HBsAg检测的标准曲线。

图2检测HBsAg的标准曲线: 横坐标是抗原浓度, 纵坐标是实时定量-PCR 的Cts回归系数。

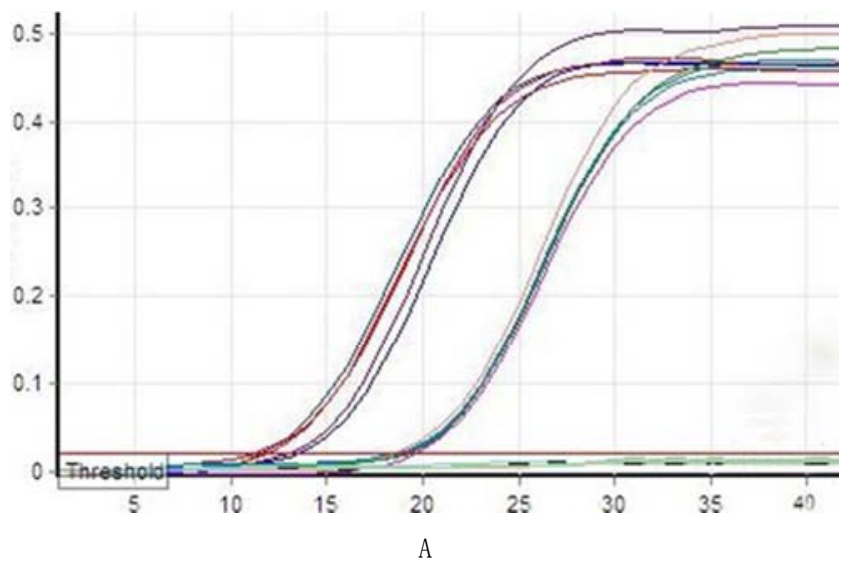

平均 CT值的标准差

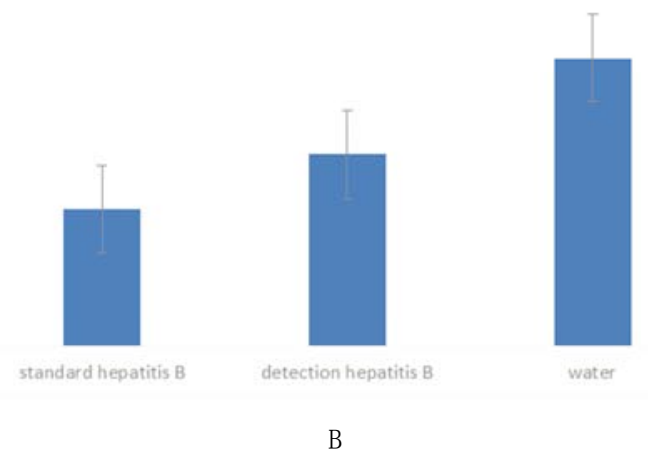

图3 磁珠免疫PCR 对HBsAg的重复检测。

如上所示A. 磁珠免疫PCR对HBsAg的重复检测的定量 曲线, B, 免疫PCR对HBsAg的重复检测15个结果的统计分析, 横坐标为标准样品 $10^{7}$ 倍稀释浓度为 $10 \mathrm{pg}$ 和待检测的乙肝 表面抗原, 纵坐标为Ct值, 结果表明其重复性高。

\section{2. 酶联免疫ELISA方法对HBsAg的检测}

乙肝表面抗原检测液 $0.02 \mathrm{mg} / \mathrm{m} 16$ 个依次 10 倍梯度稀 释为阳性, 1 个 $1 \% \mathrm{BSA}$ 阴性和 1 个空白对照, 进行酶联免疫 
反应检测的结果如表 2 和图 4 所示, 阳性SD值远远大于 0.05 , 果如表 3 和图 5 , 图6所示, 阳性、阴性SD值都大于 0.05 , 优势不显著，阴性SD值小于 0.05 , 优势显著。

乙肝表面抗原 $0.02 \mathrm{mg} / \mathrm{ml} 6$ 个 100 倍稀释为阳性, 1 个 优势不显著。

$1 \% B S A$ 为阴性, 1 个体系空白对照进行酶联免疫法检测的结

表2 HBsAg标准检测液的ELISA测定值。

\begin{tabular}{llllllll}
\hline HBsAg & 10 & 100 & 1000 & 10000 & 100000 & 1000000 & $1 \% B S A$ \\
& 1.083 & 0.973 & 0.880 & 0.726 & 0.613 & 0.551 & 0.196 \\
阳性均值 & 1.090 & 0.955 & 0.892 & 0.730 & 0.600 & 0.520 & 0.102 \\
阴性均值 & 0.131 & & & 标准方差 & 0.204 & & \\
\hline
\end{tabular}

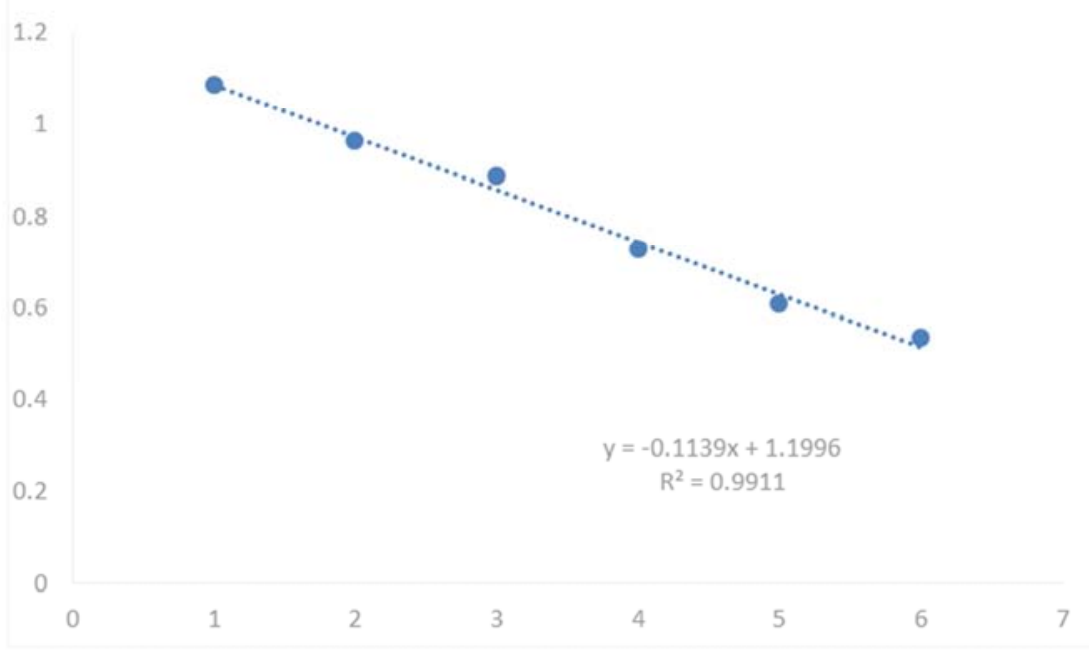

图4 10倍稀释标准品的ELISA检测。

如表 2 和图 4 所示, 其横坐标为不同浓度的 6 个样, 纵坐标为吸光值, 得出线性回归方程式是 $\mathrm{y}=-0.1138 \mathrm{x}+1.1996$ 回 归系数 $R^{2}=0.99111$ 。ELISA对 10 倍稀释的不同浓度抗原的检测基本符合线性关系。

表3 HBsAg稀释100倍ELISA的重复测定值。

\begin{tabular}{lllllllll}
\hline HBsAg & 100 & 100 & 100 & 100 & 100 & 100 & $1 \%$ BSA & 水 \\
\hline & 0.892 & 0.901 & 0.891 & 0.989 & 0.996 & 0.953 & 0.200 & 0.103 \\
阳性均值 & 0.942 & & & 阴性均值 & & 0.152 & & \\
标准方差 & 0.0571 & & & 标准方差 & & 0.0686 & & \\
\hline
\end{tabular}

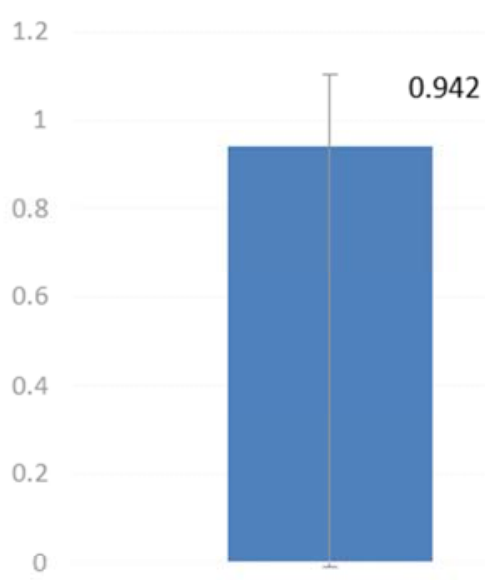

待检测液

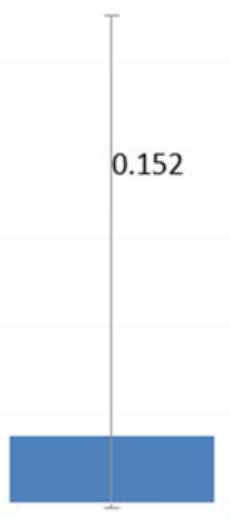

空白 


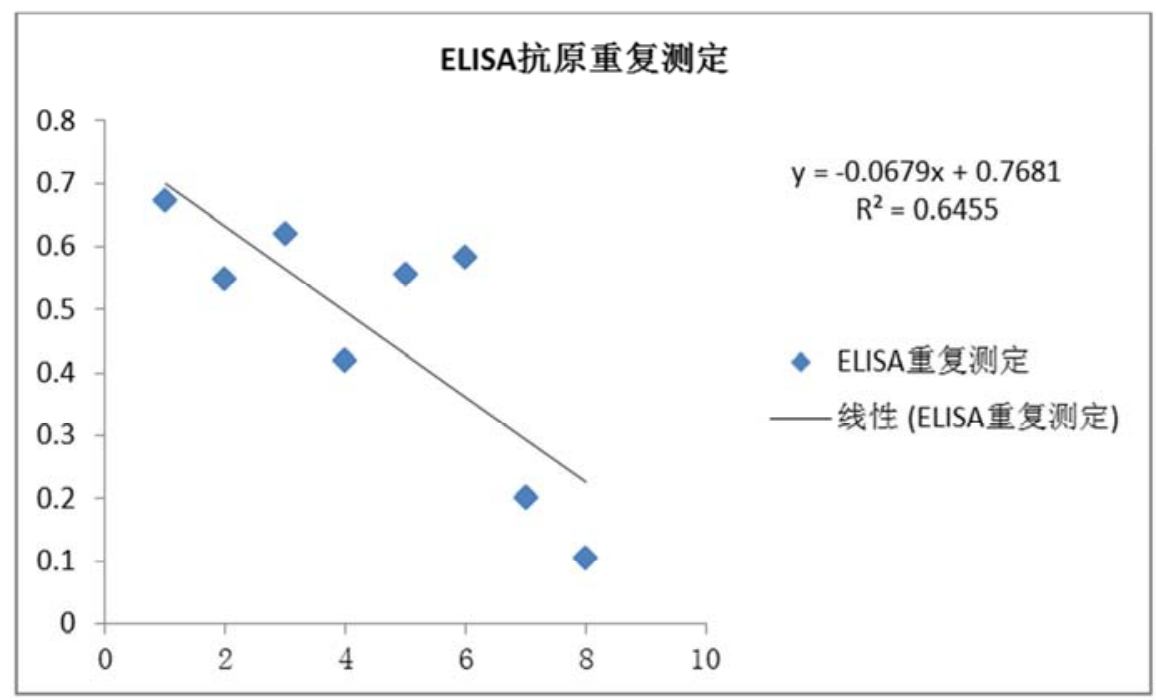

图6 ELISA对HBsAg的重复测定。

如表3和图5所示横坐标为待检测液和空白, 纵坐标为 OD值, 稀释 100 倍的 HBsAg 待检测液的吸光值的 SD值为 0.0571 大于 0.05 , 其表明相同浓度的HBsAg测定结果存在 一定的差异性。图6所示, 横坐标为 8 个样品, 纵坐标为吸 光值, 得出线性回归方程式是 $y=-0.0679 x+0.7681$ 回归系 数 $R^{2}=0.6455$, 其表明测定结果存在一定的差异性。

\section{4. 讨论}

\section{1. 酶联免疫ELISA的优缺点}

1）酶免疫试验之所以能成为临床免疫检验中的主导 技术, 是与它的方法上的特异性和灵敏性、操作上的简便 性以及试剂的稳定性分不开的, 还有很重要的一点是, 其 对环境没有污染威胁。酶免疫试验在实验过程, 影响结果 的因素也很多，尤其是进行手工的ELISA测定时。HBsAg 的测定主要是弱阳性的问题, 这与ELISA测定的 “灰区” 有关系，处于cut-off值周围亦即 “灰区” 的结果的可靠 性通常较差, 阳性当然需要确认, 阴性却也未必是真。[11]

2) 另外, 双抗体夹心法 (sandwich ELISA) 被检测 的抗原包被在两个抗体之间, 其中一个抗体将抗原固定于 固相载体上, 即捕捉抗体。另一个则是检测抗体, 此抗体 可用酶标记后直接测定抗原的量; 或不标记, 再透过酶标 记的二级抗体来测定抗原的量。这两种抗体必须小心选取, 才可避免交互反应或竞争相同的抗原结合部位。酶联免疫 吸附检测的优势是高灵敏、高专一性, 抗原无须事先纯化。 但其缺点是抗原一定得拥有两个以上的抗体结合部位。 [12]

\section{2. PCR检测的优缺点}

传统的PCR是利用琼脂糖凝胶电泳分析产物, 比较容 易出现假阳性, 实时定量PCR虽然提高了特异性和灵敏性, 但不适合快速操作, 相比之下, 日渐成熟的免疫PCR不仅 结合了PCR的高灵敏性结和ELISA的特异性, 而且可以避免 PCR-ELISA法可能出现的上述问题。[11]

\section{3. 核酸信标配基检测的优点}

本实验是用一段已知的核酸信标序列作为探针, 用此 探针与待测抗原的特异性抗体 (乙肝小鼠抗人的 IgG抗体) 的 Fc片段反应, PCR扩增与 Fc片段特异性结合的这段核酸 信标配基分子，根据特异性PCR产物的有无，来判断待测 乙型肝炎病毒表面抗原是否存在，此次构建的核酸信标配 基完全具有配体识别能力和信号储存、传递、放大功能, 是一种全新的, 构建灵活, 检测特异性强, 灵敏度高, 使 用范围广的检测分子。

为了证明本实验所采用的免疫PCR检测技术的可行性 和实验的准确性, 该实验对此技术方法进行了下面的验证 和改进。

1) 在灵敏度方面, 通过HBsAg的浓度梯度进行酶联免 疫ELISA检测和核酸信标配基-PCR检测的对比可以 看出核酸信标配基-PCR检测相比核酸信标配基实 时定量PCR检测更规律，从检测曲线的线性变化可 以看出该检测方法灵敏度更高。因为核酸信标配基 实时定量不仅具有分子识别还通过PCR指数级和荧 光双重放大信号, 而ELISA是酶的催化倍数和荧光 信号双重放大, 在数量级上有理论差。本实验 $\mathrm{PCR}$ 检测定量域在 $10^{5} \sim 10^{8}$, 而ELISA检测在 $10^{3} \sim 10^{6}$ 由此说明核酸信标配基实时定量检测的灵敏度高 于普通的酶联免疫检测。

2) 在重复性方面, 实验结果由SD值为 0.0571 大于 0.05 表明相同浓度的HBsAg酶联免疫法测定的值有差异, 而PCR 结果其Ct值 $\mathrm{SD}$ 值不足 0.05 表明检测曲线基本 重合, 证明了该方法具有一定的重复性和准确性。

3) 减少非特异性结合的处理, 非特异性吸附在一定程 度上会降低反应灵敏度, 在羧基琼脂糖磁珠结合小 鼠抗人IgG单克隆抗体的Fc片段的核酸信标配基之 前加入 $1000 \mathrm{u} 1$ 含 $1 \% \mathrm{BSA}$ 的封闭液, $37^{\circ} \mathrm{C}$ 封闭 $1 \mathrm{~h}$, 可 以提高琼脂糖磁珠对特异性ssDNA的吸附, 增强反 应灵敏度, 提高检测准确度。 
4) 减少PCR污染的处理, 每次都设置阴性对照和空白 对照。[13]

本实验应用基于核酸信标配基的磁珠夹心免疫PCR技 术，方便、快速、稳定、灵敏、特异性检地测到乙型肝炎 病毒表面抗原。本文认为核酸信标配基磁珠免疫－PCR方 法可拓宽至临床医学、[14, 15]试剂诊断、[16]食品安全、 $[17,18]$ 动物疾病诊断、 $[19,20]$ 农业环境等方面。 [21]

\section{5. 结论}

本文以羧基琼脂糖磁珠为分离载体, 基于核酸信标配 基的抗原抗体特异性反应构建了磁珠-多抗-抗原-单抗配基信标复合物夹心法模型结合Real Time-PCR检测技 术, 成功检测到了微量乙肝表面抗原蛋白（HBsAg），并 此方法与ELISA方法对比得出结论: ELISA检测乙肝表面抗 原的浓度是 $10^{2} \sim 10^{5}$ 而核酸信标配基实时定量PCR的定量域 在 $10^{5} \sim 10^{8}$, 其检测灵敏度高于普通酶联免疫检测。ELISA 检测结果不理想的另一个原因是双抗体夹心法的抗原需 有 2 个或 2 个以上的抗体联系位点, 所以其重复性不高, 最 主要的原因是虽然ELISA检测技术非常成熟, 但它只是临 床诊断的辅助手段, 其敏感性和特异性都有待提高。核酸 信标配基免疫-PCR检测方法明显优于ELISA方法, 其优点 在于用核酸信标配基代替二抗，结合Real time-PCR检测 技术具有操作简单、直观、重复率强、灵敏度高的特点, 其灵敏度达到 $10^{3}$ 倍能够方便地拓展到基于其他适配子的 微量蛋白的检测, 使乙肝的早期诊断和治疗前进了一步。

\section{致谢}

本文由国家自然科学基金(编号81360333、81360333、 81360333) 的支持和其中一部分。作者要感谢甘肃省医学 科学院实验室分子生物学提供一个技术平台和兰州大学 的人力支持。

\section{参考文献}

[1] Liu CJ, Liou JM, Chen DS, Chen PJ (2005) Natural course and treatment of dual hepatitis B virus and hepatitis C virus infections. J Formos Med Assoc 104: 783-791.

[2] Verheyen J, Neumann-Fraune M, Berg T, Kaiser R, Obermeier M (2012) The detection of HBsAg mutants expressed in vitro using two different quantitative HBsAg assays. J Clin Virol 54: 279-281.

[3] 沈耕荣重症肝炎 [M] 天津: 天津科学技术出版社, 1998:56-58.

[4] Ocama P, Opio CK, Lee WM (2005) Hepatitis B virus infection: current status. Am J Med 118: 1413.

[5] YU Qiang PW-m, ZHANG Han, XI Qi-hui. Department of Infectious (2012) The clinical significance of the quantitative detection of HBsAg and HBeAg in acute and chronic hepatitis B. Modern Preventive Medicine.

[6] OU Yang-ying LW, CHEN Yu-han, et al (2011) Comparing the efficacy of monotherapy versus combination therapy of nucleos ( $t$ ) ide analogues for decompensated HBV liver cirrhosis. Beijing Medical Journal.

[7] ZHANG Wei-Hua, WANG Xiao-Qing, LIAO Shi-Qi, WANG Li, MA Jin, TIAN Cai-Ping, MA Jun Oligonucleotide Ligands Specific for the Fc Fragment of IgG Mediat ed Real-Time Quantitative Immuno-PCR [J]; Letters in Biotechnology; 2012-02.

[8] Liao S, Liu Y, Zeng J, Li X, Shao N, Mao A, Wang L, Ma J, Cen H, Wang Y, Zhang X, Zhang R, Wei Z, Wang X. Aptamer-Based Sensitive Detection of Target Molecules via RT-PCR Signal Amplification. Bioconjug Chem. (2010) Dec 15; 21(12) : 2183-9.

[9] 李冉. Melphalan磁性微球的制备及性能研究 [D]. 武汉: 武 汉理工大学, 2012 .

[10］毛跟年; 睢建波; 齐风; 李金; 郭倩; 甘露低聚糖磁性微球制 备工艺研究 $[\mathrm{J}]$; 食品科技; 2011 年 01 期.

[11] Xu Ruihuan, jian-xia Chen, Three different methods to detect the diagnosis performance comparison of hepatitis b virus international journal of laboratory medicine (2016) May Vol. 37, No. 10.

[12] Wang Haoyu, ledong, yong-li Yang. Polymerase chain reaction (PCR) in combination with enzyme-linked immunosorbent assay to detect mycoplasma pneumoniae infection in clinical research $[\mathrm{A}]$. Chinese journal of traditional Chinese medicine, \{2015) album: grassroots medical institutions from personnel of course of science and technology thesis writing training conference proceedings [C]. (2016).

[13] Menon JU, Jade ja P, Tambe P, Vu K, Yuan B, et al. (2013) Nanomaterials for photo-based diagnostic and therapeutic applications. Theranostics 3: 152-166.

[14] Dinesh B, Peter M. Immuno magnetic bead - based recovery and real time quantitative PCR (RT iq PCR) for sensitive quantification of aflatoxin B( 1$)$ [J]. Journal of Microbiological Methods, (2011) 86( 2): $188-194$.

[15] X Y Meng , Y S Li, Y Zhou, et al. Real-time immune-PCR for ultrasensitive detection of pyrene and other homologous PAHs $[\mathrm{J}]$. Biosensors and Bioelectronics 70 (2015) 42-47.

[16] Gregersen J.P. and Roth B. 2012. Inactivation of stable viruses in cell culture facilities by peracetic acid fogging. Biologicals. Mar 15.

[17] He X, McMahon S, McKeon TA et al (2010) Development of a novel immuno-PCR assay for detection of ricin in ground beef, liquid chicken egg, and milk. J Food Prot 73: $695-700$. 
[18] College of Fujian Agriclture and Forestry University, Fuzhou 350002, Fujian, China);Common Heavy Metal Pollution in Food and Analysis Technologies [J]; Quality and Technical Supervision Research; 2010-06.

[19] Ding Y Z, Liu Y S, Zhou J H, et al. A highly sensitive detection for foot-and-mouth disease virus by gold nanopariticle improved immuno - PCR [J]. Virology Journal, (2011) 8: 148-152.
[20] D. Bu, H. S. Zhuang, X. C. Zhou and G. X. Yang, Biotinstreptavidin enzyme-linked immunosorbent assay for detecting Tetrabromobisphenol A in electronic waste, Talanta, (2014) 120, $40-46$.

[21] University, Dalian 116023, China);Establishment of monoclonal antibody mediated indirect ELISA for detection of Shewanella smarisflavi [J]; Journal of Dalian 0cean University; 2010-06. 